\title{
Increasing asthma prevalence in a rural New Zealand adolescent population: 1975-89
}

\author{
R A Shaw, J Crane, T V O’Donnell, L E Porteous, E D Coleman
}

\begin{abstract}
A survey of asthma symptoms and spirometry in 435 adolescent schoolchildren was undertaken in 1989 in a rural, largely Maori population. The survey questionnaires were identical to those used in a 1975 survey at the same school. The prevalence of reported asthma or wheeze significantly increased from $26 \cdot 2 \%$ to $34 \cdot 0 \%$. This increase occurred in groups reporting asthma, and also those reporting wheeze unassociated with colds, but without a previous diagnosis of asthma. There was a tendency for a rise in reported wheeze in Europeans (24.3\% to $27.4 \%)$ and a significant rise in Maoris (27.1\% to $36 \cdot 2 \%)$. The reclassification of other respiratory problems did not account for the increase. Data from this study provides evidence that there has been a rise in the prevalence of asthma in this New Zealand population over a time period of 14 years.
\end{abstract}

As New Zealand has had a higher mortality rate from asthma compared with other Western countries $^{12}$ there has been interest in the prevalence of asthma, and whether or not this is changing. A higher mortality rate from asthma at some ages among Maoris, ${ }^{34}$ and the higher rate for hospital admissions among Maori children, ${ }^{5}$ has also stimulated interest in the prevalence of asthma among this cultural group.

Most studies of asthma prevalence in this country have been undertaken in urban areas. One of the few studies in a rural area was by Stanhope et al, who undertook a large survey of adolescent health in Wairoa College third to fifth form students (age 12-18 years) in Hawkes Bay in $1975 .^{7}$ This included questions relating to asthma, wheeze, and respiratory health, a clinical chest examination, and baseline spirometry. According to census data the Wairoa area has changed little over the last 14 years in total population and in terms of the racial and socioeconomic structure. Wairoa College remains the only secondary school in the area taking students from both the rural farming district and the local towns. This, therefore, was an appropriate population in which to compare current asthma prevalence with that of 14 years ago.

From a survey of current Wairoa College students we report the prevalence of asthma symptoms in a rural New Zealand teenage population, of which a high proportion were of Maori origin. In addition we report the changes in prevalence of asthma symptoms in this population after 14 years.

\section{Methods}

The current survey was performed over four weeks, during August and September 1989. Each participating student was given a questionnaire, which was completed at home with the help of a parent if necessary. A structured interview followed at school. The survey technique and format of the questions were identical to those used in the 1975 survey. The following questions on asthma symptoms were asked: 'Does your chest ever sound wheezy?', followed by 'Does this wheezing happen only with colds?' Further questions involved frequency of wheezing, and also separately the presence and frequency of what was considered asthma, either based on a previous medical diagnosis, or opinion of the subject and family. According to the responses to these questions, the students were grouped into the following categories. The category names in brackets are those originally devised by Stanhope et al and are important for our comparison.

(1) No history of asthma or wheeze.

(2) Previous wheeze only with colds-one or more episodes of wheeze, not labelled asthma, but only in association with a cold, and occurring before the last year (inactive wheeze).

(3) Current wheeze only with colds-one or more episodes of wheeze not labelled asthma occurring during the last year, but only in association with a cold (active wheeze).

(4) Previous wheeze- one or more episodes of wheeze not labelled asthma, but not just associated with a cold, and occurring before the last year.

(5) Current wheeze-one or more episodes of wheeze not labelled asthma, but not just associated with a cold, occurring during the last year (subclinical asthma).

(6) Previous asthma-one or more episodes labelled as asthma by the student, but occurring before the last year (inactive asthma).

(7) Current asthma-one or more episodes labelled as asthma by the student occurring during the last year (active asthma).

Information on smoking was ascertained at the school interview. Those who had smoked at least one cigarette within the last month were defined as current smokers. Each student was also asked if he/she had ever had pneumonia or bronchitis, and a list of all medications used within the last month was requested on the home questionnaire.

Socioeconomic state was rated by father's occupation using the Congalton-Havighurst scale. ${ }^{8}$ This scale provides a series of levels from one (highest) to seven (lowest), with the addi- 
tion of an eighth level for parents either absent or not working. The eighth category was excluded in the calculation of the median score. This format was similar to that followed in the earlier survey. ${ }^{9}$

Ethnicity was determined by the question 'What is your ethnic origin?', with prompting of the possible responses of one or more of: European, New Zealand Maori, Pacific Island Polynesian, or other. In this analysis of both surveys, Maoris include all those who reported at least part Maori origin, and non-Maoris the remainder.

The forced expiratory volume in one second $\left(F E V_{1}\right)$ and forced vital capacity (FVC) were measured by a Vitalgraph spirometer, which was calibrated regularly. Each subject performed at least three attempts before the best was recorded. Where relevant, bronchodilator medication was withheld for a minimum of six hours before testing. Values expressed at body temperature, pressure, and saturation (BTPS) were compared with the Knudson standard tables for 12 to 20 year olds. ${ }^{10}$

Chest ausculation during both normal breathing and forced expiration was performed by either RAS or LEP.

Statistical analysis of comparisons between the 1975 and 1989 subjects were made by analysis of contingency tables, or by $t$ test. The frequencies of reported respiratory symptoms and diagnoses that were compared between the two surveys were adjusted for age, sex, and race by multiple logistic regression. The age groups both of 12 year olds and those older than 16 years included very few subjects, and so for analysis, 12 and 13 year olds were combined to form one group, as were those 16 years and older. $F E V_{1}: F V C$ ratios and $F E V_{1}$ values (expressed as percentage of the predicted value) were ranked then compared with analysis of variance as a non-parametric test. ${ }^{11}$

Ethical approval was given by the Wellington Hospital research ethical committee. Permission to undertake the study was given by the school board of trustees of Wairoa College, and consent was gained from the parents or guardians of all participating students.

\section{Results}

The response rate to question and examination in the current survey was $87 \cdot 2 \%$ of 499 third to fifth form students (age 12-18 years) attending Wairoa College. Details of the participants are shown in table 1 . Of the 64 non-responders, eight were accounted for by personal or family

Table 1 Population characteristics

\begin{tabular}{|c|c|c|}
\hline & 1975 & 1989 \\
\hline $\begin{array}{l}\text { No participating } \\
\text { Males (\%) }\end{array}$ & $\begin{array}{l}715 \\
50.9\end{array}$ & $\begin{array}{l}435 \\
54 \cdot 5\end{array}$ \\
\hline (mean) & $12 \cdot 4-18 \cdot 7(14 \cdot 7)$ & $12 \cdot 4-18 \cdot 9(15 \cdot 0)$ \\
\hline $\begin{array}{l}\text { district } \\
\text { Median socioeconomic }\end{array}$ & $11 \cdot 7$ & $11 \cdot 2$ \\
\hline $\begin{array}{l}\text { score }^{*} \\
\text { Maori }(\%) \dagger\end{array}$ & $\begin{array}{r}5 \cdot 7 \\
66 \cdot 8\end{array}$ & $\begin{array}{r}5 \cdot 7 \\
75 \cdot 4\end{array}$ \\
\hline
\end{tabular}

*According to the Congalton-Havighurst score.

tIncludes those of both full and part Maori origin. illness. The remainder did not respond to repeated personal, telephone, or mail requests.

\section{DEMOGRAPHY}

The median socioeconomic score was the same as in the earlier survey (table 1). When comparing each of the score levels between the two surveys, however, there was a significantly smaller number in the lowest level $(n=7)$ in 1989 compared with 1975 (4.1\% compared with $12 \cdot 3 \%)$. In contrast there was a significantly larger number in the special category 8 in $1989(21.8 \%$ compared with $13.0 \%$ ), which in 1975 included two unemployed $(0.3 \%)$, but in 1989 included 29 unemployed $(6 \cdot 7 \%)(p=0 \cdot 0001)$.

The percentage of students identifying as being of part or full Maori origin was significantly more in 1989 than in $1975(\mathrm{p}=0.005)$ (table 1). In our survey $98 \cdot 1 \%$ of non-Maoris were full European, and the remainder were of at least part European origin.

\section{ASTHMA AND WHEEZE}

For each of the categories involving either asthma or wheeze the prevalence was greater in 1989 than in 1975 , with the exception of wheezing only with colds. The prevalence of any identified wheeze (with or without a diagnosis of asthma) significantly increased from $26.2 \%$ in 1975 , to $34.0 \%$ in $1989(p=0.01)$. This obervation remained true when the comparison was confined to current wheeze (with or without a diagnosis of asthma $)(p=0.05)$. The overall increase in wheeze was mainly in the current or previous asthma categories, with a rise from $7.9 \%$ in 1975 (current $5.0 \%$, previous $2.9 \%$ ), to $13.3 \%$ in 1989 (current $8.0 \%$, previous $5.3 \%$, $p=0.004)$. There was also a significant increase in the proportion reporting wheeze unrelated to colds, without a previous diagnosis of asthma $(4.6 \%$ to $8.0 \%, p=0.01)$. If the definition of asthma was extended to include those who wheezed at times other than with a cold, but had had no previous diagnosis of asthma, there was in 1989 still a significantly greater proportion of asthmatics $(21.4 \%$ in 1989 compared with $12.6 \%$ in $1975, \mathrm{p}<0.0001)$. There was no significant change in the proportion reporting wheezing associated with colds without a diagnosis of asthma (12.7\% in 1989 compared with $13.6 \%$ in 1975 ) (table 2).

In $1989,35(8 \%)$ reported that they had taken medication for asthma within the previous month, whereas in 1975 only $17(2 \cdot 4 \%)$ stated they were taking treatment for asthma.

The increase in prevalence of symptoms overall occurred in both the Maori and non-Maori groups, but was more pronounced in the Maori group. The proportion of Maoris with asthma or wheeze increased from $27 \cdot 1 \%$ to $36 \cdot 2 \%$ ( $p=$ $0.01)$. The increase was less in non-Maoris $(24 \cdot 2 \%$ to $27 \cdot 4 \%)$ and did not reach significance.

In 1989 there were four subjects $(0.9 \%)$ found to have clinical wheezing, on forced expiration. This was not signficantly different from 1975 , when there were seven subjects $(1 \cdot 0 \%)$ with clinical wheezing (JM Stanhope, unpublished data). 
Table 2 Categorised responses to survey questionnaire. Results are number (\% of total)

\begin{tabular}{|c|c|c|c|c|c|c|c|c|}
\hline & \multirow{3}{*}{$\begin{array}{l}\text { No history } \\
\text { of asthma } \\
\text { or wheeze }\end{array}$} & \multicolumn{2}{|c|}{ Asthma diagnosed } & \multicolumn{4}{|c|}{ Asthma not previously recognised but: } & \multirow[t]{3}{*}{ Total } \\
\hline & & \multirow[t]{2}{*}{ Previous* } & \multirow[t]{2}{*}{ Current } & \multicolumn{2}{|c|}{$\begin{array}{l}\text { Wheeze associated } \\
\text { with a cold only }\end{array}$} & \multicolumn{2}{|c|}{$\begin{array}{l}\text { Wheeze without } \\
\text { a cold }\end{array}$} & \\
\hline & & & & Previous & Current & Previous & Current & \\
\hline $\begin{array}{l}1975 \\
1989\end{array}$ & $\begin{array}{l}528(73 \cdot 8) \\
287(66 \cdot 0)\end{array}$ & $\begin{array}{l}21(2 \cdot 9) \\
23(5 \cdot 3)\end{array}$ & $\begin{array}{l}36(5 \cdot 1) \\
35(8 \cdot 0)\end{array}$ & $\begin{array}{r}22(3 \cdot 1) \\
9(2 \cdot 1)\end{array}$ & $\begin{array}{l}75(10 \cdot 5) \\
46(10 \cdot 6)\end{array}$ & $\begin{array}{l}0 \\
5\end{array}(1 \cdot 1)$ & $\begin{array}{l}33(4 \cdot 6) \\
30(6 \cdot 9)\end{array}$ & $\begin{array}{l}715 \\
435\end{array}$ \\
\hline
\end{tabular}

*Before the past 12 months only; fwithin the past 12 months.

\section{ASSOCIATED FEATURES}

A history of bronchitis was reported in $16.1 \%$ in the current survey, which was not significantly different either in total from the earlier survey $(16 \cdot 2 \%)$, or when each symptom category was compared (table 3 ).

Previous pneumonia was reported significantly less often in 1989 compared with 1975 (5.5\% compared with $15 \cdot 1 \%, p=0.0001$ ) (JM Stanhope, unpublished data). This trend was identified in both symptomatic and asymptomatic groups (table 3 ).

Current smoking was significantly less reported in the 1989 survey than in the 1975 survey $(p<0.0001)$. This trend occurred in both symptomatic and asymptomatic groups (table 3). A more detailed analysis of smoking habits over the time period will be discussed in a further paper.

The percentage reporting winter coughs of at least four weeks' duration had not changed (JM Stanhope, unpublished data). In each of the symptomatic and asymptomatic categories the prevalence was similar between the two surveys (table 3).

\section{SPIROMETRY}

The mean $\mathrm{FEV}_{1}$ (\% predicted) was $109.0 \%$ in the current survey. There was, however, no sig-

Table 3 Proportions reporting other respiratory conditions according to asthma symptom category

\begin{tabular}{|c|c|c|c|}
\hline & $\begin{array}{l}\text { No asthmal } \\
\text { wheeze }\end{array}$ & $\begin{array}{l}\text { Asthmal } \\
\text { wheeze }\end{array}$ & Overall \\
\hline \multicolumn{4}{|c|}{$\%$ Of each symptomatic category: } \\
\hline $\begin{array}{l}1975 \\
1989\end{array}$ & $\begin{array}{r}11 \cdot 6 \\
9 \cdot 1\end{array}$ & $\begin{array}{l}29 \cdot 4 \\
29 \cdot 7\end{array}$ & $\begin{array}{l}16 \cdot 2 \\
16 \cdot 1\end{array}$ \\
\hline \multicolumn{4}{|l|}{ Pneumonia history } \\
\hline $\begin{array}{l}1975 \\
1989\end{array}$ & $\begin{array}{r}14 \cdot 0 \\
4 \cdot 5\end{array}$ & $\begin{array}{r}18 \cdot 1 \\
7 \cdot 4\end{array}$ & $\begin{array}{r}15 \cdot 1 \\
5 \cdot 5\end{array}$ \\
\hline \multicolumn{4}{|l|}{ Prolonged winter cough* } \\
\hline $\begin{array}{l}1975 \\
1989\end{array}$ & $\begin{array}{l}6 \cdot 6 \\
5 \cdot 1\end{array}$ & $\begin{array}{l}15 \cdot 5 \\
16 \cdot 9\end{array}$ & $\begin{array}{l}9 \cdot 0 \\
9 \cdot 2\end{array}$ \\
\hline \multicolumn{4}{|l|}{ Current smokingt } \\
\hline $\begin{array}{l}1975 \\
1989\end{array}$ & $\begin{array}{l}42 \cdot 4 \\
29 \cdot 6\end{array}$ & $\begin{array}{l}54 \cdot 5 \\
41 \cdot 9\end{array}$ & $\begin{array}{l}45 \cdot 6 \\
33 \cdot 8\end{array}$ \\
\hline
\end{tabular}

* $\geqslant 4$ weeks per year: tat least one cigarette smoked within the previous month.

Table 4 Mean spirometric values for 1989 population. Results are \% (SD)

\begin{tabular}{|c|c|c|}
\hline Asthma categories & $\begin{array}{l}F E V_{1} \\
\text { predicted }^{*}\end{array}$ & $\underset{\text { ratio }}{F E V_{1}: F V C}$ \\
\hline $\begin{array}{l}\text { No wheeze } \\
\text { Previous asthmat } \\
\text { Current asthmaf } \\
\text { Previous wheeze, only with colds } 5 \\
\text { Current wheeze, only with colds } \\
\text { Previous wheeze without colds } \\
\text { Current wheeze without colds }\end{array}$ & $\begin{aligned} & 109 \cdot 3(11 \cdot 9) \\
& 107 \cdot 8(10 \cdot 5) \\
& 105 \cdot 8(13 \cdot 3) \\
& 109 \cdot 2(10 \cdot 1) \\
& 110 \cdot 9(11 \cdot 2) \\
& 103 \cdot 6(9 \cdot 3) \\
& 109 \cdot 1(12 \cdot 7)\end{aligned}$ & $\begin{array}{l}91 \cdot 8(4 \cdot 8) \\
91 \cdot 4(6 \cdot 2) \\
88 \cdot 2(7 \cdot 3) \\
92 \cdot 6(4 \cdot 8) \\
90 \cdot 5(5 \cdot 1) \\
92 \cdot 2(5 \cdot 7) \\
92 \cdot 0(5 \cdot 3)\end{array}$ \\
\hline
\end{tabular}

nificant difference in this value between any of the asthma categories. The mean $\mathrm{FEV}_{1}: \mathrm{FVC}$ ratio was $91 \cdot 4 \%$. Those reporting current asthma had a significantly lower $\mathrm{FEV}_{1}: \mathrm{FVC}$ ratio $(88 \cdot 2 \%)$ than the combined remainder of the population $(91.7 \%)(p=0.003)$. There was no difference in this ratio between the asthma categories other than current asthma (table 4).

\section{Discussion}

There are obviously several factors which make difficult a close comparison of the prevalence of asthma through two surveys 14 years apart. There is now an increased awareness of asthma and its potential seriousness among both doctors and the wider community. Differences in cultural and socioeconomic characteristics of populations being compared may also contribute to doubt over the validity of results. Prevalence rates may differ between the different cultural groups, which are partly explained by differences in the understanding of, and interpretation of, questionnaires. There is no universally agreed definition of asthma nor a 'gold reference standard' test for asthma in survey work, and methods used 14 years apart are often not identical.

In 1982 Mitchell attempted to provide a comparison of asthma prevalence over time, in a population of 11 to 13 year old children living in an urban area in New Zealand. ${ }^{12}$ He performed an identical study to that done by Milne in $1969,,^{13}$ and from these findings concluded an increase in asthma prevalence from $7 \cdot 1 \%$ to $13.5 \%$ in this population. The racial and cultural structure of the group had however changed considerably over this time period, with a significant influx of immigrant Pacific Islanders to the area. This, along with the simplicity of the questionnaire involving just one question of 'Has this child suffered from asthma?' throws doubt on the validity of this conclusion.

In the present survey the methodology was almost identical to that of the earlier survey, and as the cultural and socioeconomic characteristics of the population have changed little with time, a valid comparison can be made. We have made our comparisons using the categories employed by Stanhope et al, but our results can be grouped according to currently acceptable criteria. In this paper we have presented the data obtained from questionnaires and spirometry. The prevalence of bronchial hyperresponsiveness and atopy and their association with symptoms will be dicussed in a subsequent paper.

Our survey questionnaire differed only 
slightly from that used in 1975 . The difference concerned ethnicity. The question asked in 1975 is now not culturally appropriate and for our 1989 survey we used the more general question on ethnic origin as in our national census. The general ethnic information sought by the question in each survey however was similar.

The 1975 survey was performed during April and May and our 1989 survey in August and September. As the questionnaires requested information on symptoms occurring both at any time previously and more specifically over the last year, however, the timing would have at most only a minor influence on responses. This difference in timing does however account for the slight difference in mean age between the two surveys. The school survey population is smaller than in 1975 just as New Zealand's population in this age group had decreased.

In the Wairoa adolescent student population the prevalence of any symptom of asthma or wheeze has increased by about $30 \%$ over the past 14 years. Within the symptomatic group there is an increase of nearly two thirds among those with a previous diagnosis of asthma, which is repeated in the group reporting wheezing other than with a cold, but with no previous diagnosis of asthma. In contrast, however, there is no difference in those reporting wheezing only with colds, without a diagnosis of asthma.

There was, however, an increase in students of at least part Maori origin in the 1989 survey and the incidence of asthma or wheeze increased more among Maoris than Europeans. This was taken into account by the adjustment for racial origin in the logistic regression analysis. Therefore a difference in proportion with Maori racial origin does not explain the rise in asthma symptom prevalence.

This significant increase in diagnosed asthma may be in part due to an increase in doctor awareness of asthma in the area. If the change in prevalence of asthma were due in part to a reclassification of wheezy illnesses, however, it would be expected that the numbers in the each of the non-asthma wheeze categories would have decreased proportionally, and there would be no change overall in those with any symptom of asthma or wheeze. Hill et al also found a large increase in reported asthma in a population of young schoolchildren between 1985 and 1988, although they found no increase in the prevalence of wheeze overall. ${ }^{14}$ From this they concluded that the increase in the prevalence of asthma was inaccurate, and probably due to a change in diagnostic habits over the time period. In our study, although there is evidence for a slight increase in the diagnosis of asthma in those who wheeze, this does not account for our findings.

In the past there has been a tendency for asthma to be misdiagnosed as bronchitis in the paediatric age group. There has been no decrease in the frequency of bronchitis over the time period, however, as would be expected if this further change in diagnostic habits was contributing to the rise in asthma. There was a drop in the prevalence of pneumonia. This has occurred proportionally in both asymptomatic and symptomatic groups, which indicates that this once again does not reflect a reclassification of illnesses.

The proportion of the current population reporting asthma $(13.3 \%)$ is consistent with the findings in Auckland, New Zealand in 1985 $(14 \cdot 2 \%)$, despite there being a younger age group (7-10 years) involved. ${ }^{15}$ In Auckland the prevalence of 'any current wheeze' (within the last 12 months) was $22 \cdot 2 \%$ in Maoris, which was significantly greater than in Europeans (16.1\%). A similar trend was seen in the current survey with $27 \cdot 1 \%$ of Maoris reporing current wheeze, and $20.6 \%$ of non-Maoris. This difference did not reach significance probably due to our smaller numbers.

The numbers using asthma treatment has also risen greatly, and in excess of the increase in asthma prevalence. This rise may reflect the improvement in medical understanding of asthma. There were three subjects on asthma medications who did not report asthma, which suggests that the asthma group may have been slightly larger had their family doctors been surveyed. The lack of increase in numbers found to be wheezing on the day may be in part explained by the increase in medications, although the numbers in this category were very small. This observation is in contrast to findings when younger age groups have been studied, when much higher numbers have been found to be wheezing when examined. ${ }^{16}$

Chronic cough, although a frequent symptom of uncontrolled asthma in small children, occurs far less frequently as a major symptom of asthma in adolescents and adults. The prevalence of prolonged ( $\geqslant 4$ weeks) winter cough has not changed either overall, or within each of the two groups of those with and without asthma symptoms. This indicates that in the majority the diagnosed cause of the cough remains separate from the diagnosis of asthma. This gives further support to the conclusion of a true rise in asthma symptoms, rather than merely a reclassification of illnesses.

Our functional assessment using spirometry differed from that of Stanhope et al and no comparison of results between 1975 and 1989 is appropriate. We are however able to further define the current population by means of spirometry. Although there were no significant differences between asthma categories in $\mathrm{FEV}_{1}$ values expressed as a percentage of predicted, those reporting current asthma did have a significantly lower mean $\mathrm{FEV}_{1}: \mathrm{FVC}$ ratio than the combined remainder of the population, as may be expected among those with current obstructive disease.

In conclusion we provide evidence that the prevalence of asthma symptoms has increased among adolescents in a rural New Zealand community. This increase cannot satisfactorily be explained by a change in diagnostic classifications, as there is no fall in numbers of subjects reporting wheezing without a diagnosis of asthma. There is no change in percentages with chronic cough, particularly in the asymptomatic group, and there is also no change in numbers reporting previous bronchitis over the time period. The reason for this increase in asthma symptoms is unclear from this study. A number 
of hypotheses have been raised, including that of increased maternal smoking during pregnancy leading to increased fetal serum IgE concentrations and subsequent atopy. ${ }^{17}$ Change in family size leading to a decrease in respiratory infections in early life has also been postulated as a possible contributing factor. ${ }^{18}$ Further investigation in this area is required.

We would like to thank the students, parents, and teachers of Wairoa College for their cooperation and help with this study, Raewyn Bull and Diane Keane for technical assistance with the survey, and Gordon Purdie for his help with the statistical analysis. The study was supported financially by the Marjorie Barclay sis. The sudy waw sure Trust. Roby ship from partially supported by the Medical Research Council of New

1 Jackson RT, Beaglehole R, Rea HH, Sutherland DC. Mortality from asthma: a new epidemic in New Zealand. BrMed $\mathcal{F}$ 1982;285:771-4.

2 Jackson RT, Sears MD, Beaglehole R, Rea HH. International trends in asthma mortality: 1970 to 1985 . Chest 1988;94:914-9.

3 Sutherland DC, Beaglehole R, Fenwick J, Jackson RT, Mullins $\mathrm{P}, \mathrm{Rea} \mathrm{HH}$. Death from asthma in Auckland: circum-
stances and validation of causes. NZ Med $\mathcal{J} 1984 ; 97$ : 845-8.

4 Sears MR, Rea HH, Beaglehole R, et al. Asthma mortality in New Zealand: a two year national study. NZ Med $\mathcal{f}$ 1985;98:271-5.
5 Mitchell EA, Cutler DR. Paediatric admissions to Auckland hospital for asthma from 1970-1980. NZ Med 7 1984:97:67-70.

6 Mitchell EA, Borman B. Demographic characteristics of asthma admissions to hospitals. NZ Med $\mathcal{f} 1986 ; 99: 576-9$.

7 Stanhope JM, Rees RO, Mangan AJ. Asthma and wheeze in New Zealand adolescents. NZ Med f 1979;90:279-82.

8 Forster J. Social processes in New Zealand. Auckland, New Zealand: Longman Paul, 1969.

9 Stanhope JM, Prior IAM. Smoking behaviour and respiratory health in a teenage sample: the Rotorua Lakes study 1 . NZ Med f 1975;82:71-6.

10 Knudson RJ, Lebowitz MD, Holberg CJ, Burrows B Changes in the normal maximal expiratory flow - volume curve with growing and aging Am Rev Respir Dis 1983;127:725-34.

11 Conover WJ, Iman RL. Rank transformations as a bridge between parametric and nonparametric statistics. The between parametric and nonparametric statistics. The

12 Mitchell EA. Increasing incidence of asthma in children. NZ Med f 1983;96:463-4.

13 Milne GA. The incidence of asthma in Lower Hutt. NZ Med $\mathcal{F}$ 1969;70:27-9.

14 Hill R, Williams J, Tattersfield A, Britton J. Change in use of asthma as a diagnostic label for wheezing illness in schoolchildren. Br Med F 1989;299:898.

15 Asher MI, Pattemore PK, Harrison AC, et al. Internationa comparison of the prevalence of asthma symptoms and bronchial hyperresponsiveness. Am Rev Respir Dis 1988;138:524-9.

16 Crane J, O'Donnell TV, Prior IAM, Waite DA. Symptoms of asthma, methacholine airway responsiveness and atopy in migrant Tokelauan children. NZ Med $\mathcal{F}$ 1989;102:36-8.

17 magnusson CG. Maternal smoking influences cord serum IgE Magnusson CG. Maternal smoking influences cord serum IgE allerg levels and increases the risk for subsequent

18 Strachan DP. Hay fever, hygiene, and household size. $B r$ Med f 1989;299:1259-60. 